\title{
Transcriptome-wide characterization and functional analysis of MATE transporters in response to aluminum toxicity in Medicago sativa $\mathbf{L}$.
}

\author{
Xueyang Min 1, 2,3,4 , Xiaoyu Jin 1,2,3,4 , Wenxian Liu Corresp., 1,2,3,4 , Xingyi Wei ${ }^{1,2,3,4}$, Zhengshe Zhang ${ }^{1,2,3,4}$, \\ Boniface Ndayambaza ${ }^{1,2,3,4}$, Yanrong Wang Corresp. 1, 2, 3,4 \\ ${ }^{1}$ State Key Laboratory of Grassland Agro-ecosystems \\ 2 Key Laboratory of Grassland Livestock Industry Innovation, Ministry of Agriculture and Rural Affairs \\ 3 Engineering Research Center of Grassland Industry, Ministry of Education \\ 4 College of Pastoral Agriculture Science and Technology, Lanzhou University, Lanzhou, 730020, P. R. China \\ Corresponding Authors: Wenxian Liu, Yanrong Wang \\ Email address: liuwx@lzu.edu.cn, yrwang@lzu.edu.cn
}

Multidrug and toxic compound extrusion (MATE) transporters contribute to multidrug resistance and play major determinants of aluminum (Al) tolerance in plants. Alfalfa (Medicago sativa L.) is the most extensively cultivated forage crop in the world, yet most alfalfa cultivars are not Al tolerant. The basic knowledge of the MATE transcripts family and the characterization of specific MATE members involved in alfalfa Al stress remain unclear. In this study, 88 alfalfa MATE (MSMATE) transporters were identified at the whole transcriptome level. Phylogenetic analysis classified them into four subfamilies comprising eleven subgroups. Generally, five kinds of motifs were found in group G1, and most were located at the N-terminus, which might confer these genes with Al detoxification functions. Furthermore, ten putative Al detoxification-related MSMATE genes were identified and the expression of five genes was significantly increased after Al treatment, indicating that these genes might play important roles in conferring Al tolerance to alfalfa. Considering the limited functional understanding of MATE transcripts in alfalfa, our findings will be valuable for the functional investigation and application of this family in alfalfa. 
1 Transcriptome-wide characterization and functional analysis of MATE transporters in 2 response to aluminum toxicity in Medicago sativa $\mathbf{L}$.

3 Xueyang Min, Xiaoyu Jin, Wenxian Liu*, Xingyi Wei, Zhengshe Zhang, 4 Boniface NDAYAMBAZA \& Yanrong Wang*

5 State Key Laboratory of Grassland Agro-ecosystems; Key Laboratory of Grassland Livestock

6 Industry Innovation, Ministry of Agriculture and Rural Affairs; Engineering Research Center of 7 Grassland Industry, Ministry of Education; College of Pastoral Agriculture Science and 8 Technology, Lanzhou University, Lanzhou, 730020, P. R. China

9 *Corresponding authors: Wenxian Liu, Yanrong Wang

10 E-mail: liuwx@1zu.edu.cn, yrwang@1zu.edu.cn

11 Tel: +86-931-891-2486; Fax: +86-931-891-2486. 


\section{ABSTRACT}

14 Multidrug and toxic compound extrusion (MATE) transporters contribute to multidrug resistance 15 and play major determinants of aluminum (Al) tolerance in plants. Alfalfa (Medicago sativa L.) is 16 the most extensively cultivated forage crop in the world, yet most alfalfa cultivars are not Al 17 tolerant. The basic knowledge of the MATE transcripts family and the characterization of specific MATE members involved in alfalfa Al stress remain unclear. In this study, 88 alfalfa MATE (MsMATE) transporters were identified at the whole transcriptome level. Phylogenetic analysis classified them into four subfamilies comprising eleven subgroups. Generally, five kinds of motifs were found in group G1, and most were located at the N-terminus, which might confer these genes with Al detoxification functions. Furthermore, ten putative Al detoxification-related MsMATE genes were identified and the expression of five genes was significantly increased after Al 24 treatment, indicating that these genes might play important roles in conferring Al tolerance to alfalfa. Considering the limited functional understanding of MATE transcripts in alfalfa, our findings will be valuable for the functional investigation and application of this family in alfalfa.

\section{Introduction}

Aluminum (Al) is the third most predominant inorganic monomeric component in the outside layer. Roughly $30 \%$ of the ice-free land area comprises the best soil with a $\mathrm{pH}<5.5$, and half of the world's conceivably arable grounds are acidic (Kochian et al. 2004; Vonuexkull \& Mutert 1995). Unlike other metals, Al toxicity is much more threat to plant grown in acidic soil, and it remains quite toxic to plant roots and inhibits root elongation, further leading to roots stunting accompanied by reduced water and nutrients uptake (Kochian et al. 2004; Wood et al. 2000). For Al toxicity, two mechanisms that encourage $\mathrm{Al}$ tolerance in plants are preventing $\mathrm{Al}$ particles from entering the roots (exclusion mechanism) and detoxifying internal Al in the symplast (tolerance

37 mechanism) (Ma et al. 2001; Sade et al. 2016; Zheng et al. 2005). Many Al-accumulating plants, 
38

39

40

41

42

43

44

45

46

47

48

49

50

51

52

53

54

55

56

57

58

59

60

61

62

63

such as Melastoma malabathricum and buckwheat, possess the inner Al detoxification ability to form the development of metal and accumulating them in the above-ground herbage (Ma et al. 2001; Zheng et al. 2005). Another mechanism of Al tolerance in plants involves Al initiation of membrane transporters that intercede organic acid (OA; such as malate, citrate, and oxalate) exclusion from the root apex and form non-toxic complexes with rhizosphere aluminium (Kochian et al. 2004; Sade et al. 2016). The mechanism of Al tolerance has reported in many crops, such as rice, wheat, soybean, maize, sorghum, buckwheat, and rye (Kochian 1995; Kochian et al. 2005; Ma et al. 2001; Zheng et al. 2005). Recently, the root apex has also recommended to role in Al tolerance, which is related to serious changes in the root system, including cell differentiation in root tips and lateral roots, increasing cell wall inflexibility, interfering with several enzymes, reducing DNA replication, modifying the structure and capacity of plasma membranes, and disrupting signal transduction pathways (Sade et al. 2016; Zheng et al. 2005).

The citrate transporter is an electrochemical potential-driven transporter activated by $\mathrm{Al}$ and belongs to the multidrug and toxic compound extrusion (MATE) family (Yokosho et al. 2016). A MATE gene (Norm) was cloned in Vibrio parahaemolyticus, which possesses an energy-dependent system that effluxes nofloxacin and other antimicrobial agents outside of the cells by $\mathrm{Na}^{+} / \mathrm{drug}$ antiport (Morita et al. 1998). The MATE family consists of a unique topology predicted to have 10 to 12 transmembrane (TM) helices with long, cytoplasmatic $\mathrm{C}$ and $\mathrm{N}$ termini (Motawie et al. 2016). To date, 56, 53, 117, 70, 49, 70 and 68 MATE transporters have been identified from Arabidopsis (Li et al. 2002; Liu et al. 2009), Oryza sativa (Tiwari et al. 2014), Glycine max (Liu et al. 2016), Medicago truncatula (Wang et al. 2017), Zea mays (Zhu et al. 2016), Gossypium raimondii and Gossypium arboreum (Lu et al. 2018), respectively. According to the established MATE functions, three major classes associated with disease resistance, small organic molecule exportation, and secondary metabolite transportation have been classified (Diener et al. 2001; Hiasa et al. 2006; Tiwari et al. 2014). As the first MATE transporter identified in plant, AtALF5 (Arabidopsis aberrant lateral root formation 5) was involved to the protection of roots from 
64 multidrug resistance (Diener et al. 2001). AtDTX1 (A. thaliana detoxification 1) was characterized

65 as an efflux transporter for plant-inferred alkaloids, anti-infections, and different exogenous toxic

66 compounds ( $\mathrm{Li}$ et al. 2002). MATEs have also been demonstrated to be associated with plant

67 disease resistance, such as EDS5 (enhanced disease susceptibility 5), which functions in reducing

68 basal resistance during pathogen interaction (Nawrath et al. 2002). OsMATE1 and OsMATE2

69 negatively alter stress responses and pathogen vulnerability (Tiwari et al. 2014). Additionally,

70 different research studies have also showed that MATE transporters mediate citrate efflux to

71 present plant resilience and tolerance to Al toxicity (Magalhaes et al. 2007; Wood et al. 2000).

72 Moreover, roles of some genes in this family in tolerance towards Al toxicity in acidic soils, which

73 involve an electrochemical slope of cations ( $\operatorname{such}$ as $\mathrm{H}^{+}$or $\mathrm{Na}^{+}$ions) over the film to drive substrate

74 export, have been examined (Shoji 2014). The first aluminum-activated citrate transporter,

75 SbMATE (Sorghum bicolor MATE), was characterized in sorghum (Magalhaes et al. 2007).

76 Similar to this protein from sorghum, MATE proteins from Hordeum vulgare (HvACT1)

77 (Furukawa et al. 2007), O. sativa (OsFRDL4) (Yokosho et al. 2011), Zea mays (ZmMATE1)

78 (Maron et al. 2010) and Eucalyptus camaldulensis (EcMATE1) (Sawaki et al. 2013) have

79 additionally been appeared to take an interest in Al resilience by transporting organic acid anions

80 from roots to decrease Al absorption in the rhizosphere (Ma 2000; Yokosho et al. 2016).

81 As the most widely grown perennial legume crop, alfalfa provides numerous agro-ecological

82 advantages, including a high nutritional value, a perennial high yield, contributions to soil fertility,

83 and multiple harvests during the growing season (Min et al. 2017; Wang et al. 2016). However, it

84 is responsive to soil acidity, and its production and stand duration are severely impaired by acidic

85 soils due to root growth inhibition and weakened nitrogen fixation (Hartel \& Bouton 1991; Liu et

86 al. 2017). While the existing research on MATE transporters is mostly focused on model plants,

87 the information regarding the expression and function of $M A T E$ genes related to Al stress in alfalfa

88 are still not yet reported. Here, we systematically identified the MATE family at the transcriptome-

89 wide level using a rigorous method to provide basic data regarding alfalfa MATE transporters. Our 
90 observations provided a first sight of how these Al-tolerant regulators behave when alfalfa is

91 disputed by Al stress. This fundamental research would provide the valuable information for the

92 further gene cloning and biotechnology studies of the MATE transporters in alfalfa.

\section{Materials and methods}

\section{Plant growth and Al treatment}

95 The seeds of alfalfa (cultivar Zhongmu No.1) were surface sterilized in $1.0 \%$ (v/v) sodium 96 hypochlorite for approximately $5 \mathrm{~min}$ and then tap water washed 3 times and germinated at $20^{\circ} \mathrm{C}$ 97 in the dark. After 3 days, uniform seedlings were transplanted to half-strength modified Murashige 98 and Skoog (MS) solution (pH 5.6) in plastic containers, and the solution was changed every 2 days. 99 The seedlings were grown in a growth chamber under controlled conditions (light intensity 120 $100 \mu \mathrm{mol} \mathrm{m} \mathrm{m}^{-2} \mathrm{~s}^{-1}, 16 / 8 \mathrm{~h}$ light/dark cycle at $25^{\circ} \mathrm{C}$ and a relative humidity of $65 \%$ ). After cultivating 101 for 7 days at $25^{\circ} \mathrm{C}$ with a photoperiod of $16 \mathrm{~h}$ light $/ 8 \mathrm{~h}$ dark, the seedlings were transferred to 0.5 $102 \mathrm{mM} \mathrm{CaCl}_{2}(\mathrm{pH} 4.5)$ for $24 \mathrm{~h}$ before $\mathrm{Al}$ treatment. The seedlings were then exposed to $0.5 \mathrm{mM}$ $103 \mathrm{CaCl}_{2}(\mathrm{pH} 4.5)$ solution containing either $0 \mu \mathrm{M} \mathrm{AlCl}_{3}$ (control) or $20 \mu \mathrm{M} \mathrm{AlCl}_{3}$ (treatment) for 4 $104 \mathrm{~h}, 8 \mathrm{~h}$ and $24 \mathrm{~h}$, respectively. The root tips (approximately $2 \mathrm{~cm}$ in length) were collected, both the 105 main root tips and the secondary root tips, and immediately frozen in liquid nitrogen and stored at $106-80^{\circ} \mathrm{C}$. The experiment was performed in triplicate.

\section{Sequences dataset and MATE transporter identification in alfalfa}

108 To identify novel alfalfa MATE transporters, all the alfalfa annotated unigenes were 109 downloaded from the Alfalfa Gene Index and Expression Atlas Database (AGED) (O'Rourke et 110 al. 2015). Arabidopsis (57), rice (52), M. truncatula (70) and soybean (117) MATE protein 111 sequences were collected from Phytozome v12 (Goodstein et al. 2012). Basic Local Alignment 112 Search Tool algorithms were applied with the published O. sativa, Arabidopsis, M.truncatula and 113 soybean MATE transporters as a query to search against the AGED database and with e-value 114 cutoff set as 1e-5. The conserved protein domain of these candidates was checked using NCBI115 CDD search (http://www.ncbi.nlm.nih.gov/Structure/cdd/wrpsb.cgi). If an open reading frame 
116 (ORF) contained the complete MATE domain, then CDSs were manually retrieved with ORF

117 Finder (http://www.ncbi.nlm.nih.gov/gorf/gorf.html) and translated into protein sequences in

118 Sequence Manipulation Suite (http://www.bioinformatics.org/sms2/translate.html). All the

119 obtained protein sequences were examined for the presence of MATE domains using the Pfam

120 (http://pfam.sanger.ac.uk/search) tool. Multiple alignments were also performed to avoid

121 repetition.

\section{Phylogenetic tree construction and conserved motifs identification}

123 A bootstrap neighbour-joining (NJ) phylogenetic tree was constructed among alfalfa,

124 Arabidopsis and rice MATEs using ClustalW in Clustal Omega (Mohanta et al. 2015; Sievers et 125 al. 2011), then the phylogenetic tree data was used to construct a NJ tree in MEGA 7.0 (Kumar et 126 al. 2016). Motifs of MsMATE proteins were determined using the Multiple Expectation 127 Maximization for Motif Elicitation (MEME) (http://meme-suite.org/), and a schematic diagram of 128 amino acid motifs of each MsMATE protein was drawn accordingly with the default parameters, 129 except the maximum number of motifs to find was set to 12 (Bailey et al. 2015).

\section{In silico sequence analysis}

131 The theoretical isoelectric point $(\mathrm{pI})$ and molecular weight $(\mathrm{Mw})$ of the MsMATE proteins 132 were calculated using the Param tool (http://web.expasy.org/protparam/), and subcellular 133 localization was predicted using WoLF PSORT (Horton et al. 2007). Number of transmembrane 134 helices (TMs) was predicted using TMHMM Server v. 2.0 (Krogh et al. 2001). Arabidopsis 135 orthologues for alfalfa MATE proteins were identified by a BLASTP search against Arabidopsis 136 proteins TAIR10 release (http:// www.arabidopsis.org). The functional interacting networks of 137 predicated Al detoxification MATE proteins were integrated using STRING software with the 138 confidence limit set at 0.400 (Von Mering et al. 2005). The expression data was retrieved from the 139 AGED database (NCBI accession: SRP055547), and the expression data were gene-wise 140 normalized using the MeV v4.9 software (http://www.mybiosoftware.com/). 
142

143

144

145

146

147

148

149

150

151

152

153

154

155

156

157

158

159

160

161

162

163

164

165

166

167

Total RNA was extracted from tissues using the Sangon UNIQ-10 column TRIzol total RNA extraction kit and digested using DNase I to eliminate genomic DNA contamination according to the manufacturer's instructions. Subsequently, first-strand cDNA was synthesized from $4 \mu \mathrm{g}$ of total RNA by M-MuLV reverse transcriptase (Sangon Biological Engineering Technology \& Services, China). Gene-specific primers (Table S6) for qRT-PCR analysis were designed using NCBI Primer-BLAST and their specificity was checked by blasting each primer sequence against the alfalfa transcriptome sequence. The qRT-PCR analysis was performed in three technical replicates using the 7500 Fast Real-Time PCR system (Applied Biosystems, USA). The $20 \mu$ qRTPCR mixtures included $10 \mu \mathrm{L}$ of $2 \times$ SG Fast qPCR Master Mix (Low Rox), $0.5 \mu \mathrm{L}$ of forward and reverse primers, $2 \mu \mathrm{L}$ of DNF Buffer, $1 \mu \mathrm{L}$ of diluted cDNA solution, and $6 \mu \mathrm{L}$ of ddH $\mathrm{d}_{2} \mathrm{O}$. The thermal profile for $\mathrm{qRT}-\mathrm{PCR}$ was as follows: $10 \mathrm{~min}$ at $95^{\circ} \mathrm{C}$ for DNA polymerase activation, followed by 40 cycles of $15 \mathrm{~s}$ at $95^{\circ} \mathrm{C}$ and $1 \mathrm{~min}$ at $60^{\circ} \mathrm{C}$. As an internal standard, $M s$ - $A c t i n$ was used to calculate the relative fold differences based on the comparative $C t$ method. The expression levels were calculated using the $2^{-\Delta \Delta \mathrm{CT}}$ method.

\section{Results}

\section{Identification of MSMATE transporters}

To identify the MSMATE transporters in alfalfa, the previously identified MATE proteins in several model plant species were used as a query to search the alfalfa transcriptome dataset. A total of 106 contigs with complete conserved domains and full-length cDNA sequences were identified (Table S1). After removing redundancy, 88 unique $M S M A T E$ genes finally remained for further phylogenetic and functional analysis (Table S2 and Supplementary data 1). According to their numeric sorting, the 88 genes were designated MSMATE01 - MSMATE88. The ORFs of these genes were varied in length from 321 (MsMATE14) to 1788 (MsMATE20) bp, and the predicted protein products ranged from 106 to 595 amino acids of length with molecular weight varying from 11.61 to $65.3 \mathrm{kDa}$, containing 0 to $12 \mathrm{TMs}$, the protein grand average of hydropathy varying from 0.358 (MsMATE06) to 1.159 (MsMATE22). The protein isoelectric point varied from 4.51 
168 (MsMATE12) to 10.33 (MsMATE03), suggesting that these MATE proteins may work under 169 different conditions. In addition, 63 plas (plasma membrane, 71.60\%), 10 chlo (chloroplast, $17011.36 \%$ ), 6 cyto (cytoplasm, 6.82\%), 7 vacu (vacuole, 7.95\%) and 2 nucl (nucleus, 2.27\%) were 171 found according to the subcellular location results (Table S3).

172 Phylogenetic relationship analysis of MsMATE transporters

173 To categorize and investigate the evolutionary relationships among different species, the 174 MATE proteins in alfalfa, Arabidopsis and rice were chosen to perform phylogenetic scrutiny (Fig. 1751 and Supplementary data 2). Based on DNA-binding motifs and functional properties, all these 176 MsMATE domains could be classified into four main classes including eleven smaller subgroups 177 (Fig. 1), namely, class I (subgroups CI-1, CI-2 and CI-3), class II (subgroups CII-1 and CII-2), 178 class III (subgroups CIII-1, CIII-2 and CIII-3) and class IV (subgroups CIV-1, CIV-2 and CIV-3). 179 To similarly predict and distinguish the feature of identified MsMATE genes in this study, an $180 \mathrm{NJ}$ tree was constructed using 88 MsMATE proteins and 38 MATE transporters from other 181 species, which have been well investigated at the molecular level and proved have specific function 182 (Fig. 2, Table S4). Four main distinct groups (groups G1, G2, G3 and G4) comprising 12 smaller 183 subgroups were finally identified (Fig. 2). The first group consist of 22 MsMATEs, and some 184 MATE transporters function as ligand and molecules to bind Al detoxification/iron translocation 185 in the rhizosphere. In addition, four subgroups within the first group (G1) were observed. A total 186 of 10 MsMATE proteins and all the other 19 Al detoxification/iron translocation-related genes 187 were classed into subgroups G1-3, indicating that these 10 MsMATE proteins might be concerned 188 in Al detoxification and/or iron translocation in alfalfa. Previous lookup located that 189 AtADS1/ABS3 is a negative regulator of plant disease resistance (Sun et al. 2011) and that ELS1 190 is a novel MATE transporter associated to leaf senescence and iron homeostasis in Arabidopsis 191 (Wang et al. 2016). Overexpression of AtZF14/BCD1/ABS4 and AtADS1/ABS3 in Arabidopsis 192 suggested that these MATE genes function at an increasing organ initiation rate, sustaining iron 193 homoeostasis and hypocotyl cell elongation (Burko et al. 2011; Seo et al. 2012; Wang et al. 2015). 
194 In our research, there are five MsMATE proteins classified into G2-2 with the other three MATE 195 proteins (AtADS1, ELS1 and AtZF14), G2 subgroup may has diverse physiological functions in 196 alfalfa. Group G3 (24 MsMATE proteins) could be further classified into three subgroups. 197 Subgroup G3-1 has 4 MsMATE proteins and a recognized MATE protein AtALF5 (A. thaliana 198 aberrant lateral root formation 5), which is expressed strongly in the root epidermis and expanded 199 the sensitivity of roots to a variety of compounds (Diener et al. 2001). Subgroup G3-2 incorporates 2009 MsMATE members, with no formerly acknowledged MATE proteins. There are 10 MsMATE 201 proteins in the G3-3 subgroup and two in the past mentioned MATE transporters, namely, NtJAT1 202 (N. tabacum jasmonate-inducible alkaloid transporter 1) and AtDTX1 (A. thaliana detoxification 203 1). Previous studies have showed that NtJAT1 used to be determined to characteristic as a 204 secondary transporter for nicotine translocation in tobacco (Morita et al. 2009), and AtDTX1 205 mediated plant-derived efflux and detoxified the heavy metal $\left(\mathrm{Cd}^{2+}\right)$. It also served to efflux other 206 toxic compounds ( $\mathrm{Li}$ et al. 2002). Therefore, subfamily G3 might be related to the xenobiotics and 207 alkaloid transporter. Among all the groups, G4 was once the biggest clade (including 34 208 MsMATEs) and ought to be further divided into 3 subgroups. The functions of the recognized 209 MATE transporters in this group are concerned in trafficking of secondary metabolites in vacuoles 210 and accumulating flavonoids or anthocyanin in plants. For example, the Arabidopsis TT12 211 transporter exhibits extended substrate specificity accepting glycosylated anthocyanidin in vitro

212 (Marinova et al. 2007), and AtFFT is highly transcribed in floral tissues and affects flavonoid 213 levels in Arabidopsis (Thompson et al. 2010).

\section{Conserved motifs analysis of the MSMATE transporters}

215 The composition of conserved motifs in MsMATE proteins was predicted to illustrate the protein 216 structure (Fig. 3). The motifs presented in MsMATEs ranged from 1 to 11, and the length of the 217 motifs ranged from 15 to 50 aa (Fig. S1). The types of motifs are similar amongst the G2, G3 and 218 G4 groups however differ drastically from the G1 group. The MsMATE proteins in group G1 219 commonly have five sorts of motifs, and most of them are in the N-terminal, which is less than 
220 that of other three groups, such as MsMATE11, 12, 13 and 22, which have only one type of motif.

221 The motif 9 was specifically found in group GI, except for MsMATE22. Motif 9 of G1 group 222 proteins were further determined using the Motif Alignment \& Search Tool (MAST), the ensembl 223 plant genomes protein of Arabidopsis, rice, M. truncatula and soybean as database to search 224 against motifs 9, and sort of the sequences by the best combined match to all motifs. Results 225 showed that the motif 9 was identified in four model plants, and all of them belong to MATE 226 transporter family. Based on the phylogenetic tree analysis, Al detoxification/iron translocation227 related genes (19 genes) were classed into this groups, implying that motif 9 is essential and 228 specific to MATE transporter family, and might play a crucial role in Al detoxification in alfalfa

\section{Functional identification of the MSMATE transporters}

230 Four public databases, Phytozome, GO, KEGG and UniProt Knowledgebase, were used to 231 predict MsMATE protein annotations with an e-value cut-off of 1e-10. The annotation results are 232 listed in detail in Table S5. The expected MsMATE proteins possibly take apart in xenobiotic 233 efflux, accumulation of secondary metabolites (alkaloids and flavonoids), metal translocation and 234 detoxication, and plant hormone signalling and growth regulation

235 In this study, ten MsMATE proteins predicted to participate in Al detoxification were used to 236 determine the functional and physical relationship through rice and Arabidopsis association model 237 using the STRING software, respectively (Fig. S2). Of these ten MsMATE proteins, the 238 homologous gene suits the easiest bit score by the way of default. OsFRDL4, at the centre of the 239 network node, is an Al-induced citrate transporter that is involved in Al-induced citrate secretion 240 in rice root cells (Fig S2A) (Yokosho et al. 2011). The Nramp aluminum transporter (NRAT1) 241 encodes a transporter involved in Al uptake from the root tip cell wall into the cell and plays a key 242 function in rice aluminum tolerance (Li et al. 2014; Xia et al. 2011). The Al-induced gene STAR1 243 encodes an ATP-binding protein and a transmembrane domain protein, which are required for Al 244 tolerance (Huang et al. 2009). The OsFRDL4 could potentially interact with at least 7 proteins, 245 including (NRAT1 and STAR1), indicating that it plays important role in the regulation Al- 
246 induced citrate transporter (Fig S2A). Furthermore, the dicot plant model of Arabidopsis was 247 further determined (Fig. S2B). Among the ten MsMATE proteins, MsMATE01, 02, 03, 04 and 05 248 shared a high similarity to FRD3 (FERRIC REDICTASE DEFECTIVE3), which shown to be a 249 citrate efflux transporter, the ectopic expression of FRD3-GFP possessed an enhanced resistance 250 to aluminium in Arabidopsis roots (Durrett et al. 2007). Meanwhile, MsMATE22 shared the 251 highest similarity (74\%) with AT1G51340, previous studies shown that this protein might be 252 involved in the citrate exudation into the rhizosphere to protect roots from Al toxicity (Liu et al. 253 2012; Liu et al. 2009).

\section{Expression profiles of MsMATE genes in different tissues}

255 The expression profiles of all 88 MSMATE genes at six developmental stages, namely, 256 elongating stem internodes (ES), developing flowers, mature leaf, nitrogen fixing nodules, post257 elongating stem internodes (PES) and whole root, were analysed using Illumina RNA-seq data 258 (Fig. 4). Depending on the hierarchical clustering, the MsMATE genes have various transcript 259 levels during alfalfa development. Among the 88 MsMATE genes, 5 (MsMATE 05, 22, 31, 38 and 260 82) showed an overall coverage among all developmental stages (value $>1.27$ ). In contrast, the 261 expression level of 13 MsMATE genes (MSMATE 03, 06, 14, 36, 45, 51, 52, 53, 60, 67, 72, 80 and

262

263

264

265

266

267

268

269

270

271

83) was relatively low in all tissues (value <1.27) Moreover, among the remaining $70 M S M A T E$ genes, 39, 35, 29, 23, 22 and 14 showed high expression levels (value $>1.27$ ) in the mature leaf, developing flowers, nitrogen fixing nodules, ES, whole root and PES, respectively, implying they may play important roles in the corresponding tissues. Although some MSMATE genes were classified into one subgroup, the distinct tissue expression profiles of these genes in alfalfa showed that they may have exceptional physiological roles. Furthermore, some MsMATE genes had tissuespecific expression, for example, MSMATE 02, 34, and 64 in the developing flowers; MSMATE 01, 25, 26, 46, 62, and 63 in the whole root; and MsMATE 15, 42, 43, 55, 56, 59, 76, 77 and 78 in nitrogen-fixing nodules.

Expression of the subgroup G1-3 MsMATE genes in response to Al toxicity 
As we were interested in the roles of MATE genes involved in Al stress in alfalfa, the

273

274

275

276

277

278

279

280

281

282

283

284

285

286

287

288

289

290

291

292

293

294

295

296

expression patterns of ten MsMATEs that were predicted to be Al detoxification-related based on the sequence similarity were further analysed using qRT-PCR. As shown in Fig. 5, MsMATE05 and MSMATE09 were significantly up-regulated after Al treatment. The expression of MsMATE03, MsMATE07, and MsMATE22 fluctuated across early $(4 \mathrm{~h})$, middle $(8 \mathrm{~h})$ and/or late $(24 \mathrm{~h}) \mathrm{Al}$ exposure time points. Among these five up-regulated MSMATE genes, MSMATE09 has the highest expression level, nearly up-regulated 18 -fold at time point four hours compared with control. In contrast, the expression of the five remaining genes (MsMATE01, MsMATE02, MsMATE04, MSMATE06 and MsMATE08) was significantly down-regulated after Al treatment.

\section{Discussion}

Al toxicity is a considerable hindrance of crop comprehensive completion in acidic soils worldwide. At $\mathrm{pH}$ values beneath 5, $\mathrm{Al}$ tends to be dissolved as $\mathrm{Al}^{3+}$ ions, which are quite toxic to plant roots and can further limit crop production (Kochian et al. 2015; Vonuexkull \& Mutert 1995). Thus, a sound comprehension of the mechanistic basis and gene quality giving protection of $\mathrm{Al}$ poisonous quality has been seriously explored over the final decade. To date, two major elementary sorts of Al resistance mechanisms are characterized: $\mathrm{Al}$ exclusion mechanisms and Al tolerance mechanisms. Among them, the Al-induced unharness of organic compounds preventing the contact of phytotoxic $\mathrm{Al}^{3+}$ with the Al-sensitive root apex is the best-documented mechanism (Kochian et al. 2015). The MATE family is very important cluster of multidrug effluence transporters that square measure liable of $\mathrm{Al}$ resistance support root citrate exudation in response to Al stress. Some necessary legume crops, like soybean and alfalfa, are sensitive to acidic soils as well as $\mathrm{Al}^{3+}$ environment; therefore, their development and yield could be severely restricted. However, restricted data is presented for alfalfa response to $\mathrm{Al}^{3+}$ stress, for the most part of their complicated biological science, massive genomes and complicated resistance mechanisms (Wang et al. 2017a). Currently, a total of 112,626 unigenes is publicly available for download and 
297 exploration on the AGED database (O'Rourke et al. 2015), which provides an opportunity for 298 MsMATE transporter screening and characterization in alfalfa.

299 In our study, a complete of 88 MsMATE transporters were finally known in alfalfa and this 300 number is 1.5- and 1.6-fold that of Arabidopsis and rice respectively, that is in line with the 301 magnitude relative of the full variety of transporter sequences in alfalfa thereto in genus 302 Arabidopsis and rice (Benedito et al. 2010). However, as the genome sequence of alfalfa has not 303 been released, the members of the $M S M A T E$ gene identified in this study may not be fully covered. 304 To review the organic process relationship between the MsMATE transporters and the MATE 305 transporters from completely different plant species, all MsMATEs and MATE transporters from 306 the monocot (rice) and dicot (Arabidopsis) model systems were subjected to phylogenetic 307 analyses. As illustrated in Fig. 1, the organic process tree categorized the MsMATE transporters 308 into four completely different groups along with their AtMATE and OsMATE orthologs, and ten 309 MsMATE transporters were clustered into subgroups G1-3 with 19 previously reported Al 310 detoxification genes (Fig. 2). The phylogenetic scrutiny is one of the fastest, simplest, and 311 relatively most precise way to predict gene function that may want to be subsequently prioritized 312 for further practical confirmation. Previous studies have provided strong evidence for function 313 prediction of gene families based on phylogenetic analysis, including MATE transporters (Chen 314 et al. 2015; Le et al. 2011; Liu et al. 2016). These ten MSMATE genes might be potential candidate 315 genes involved in Al tolerance in alfalfa and warrant further analysis.

316 Gene structure analysis shows that different MsMATE members in alfalfa shared a relatively 317 conserved motif distribution tend to cluster together. As shown in Fig. 3, MsMATEs in groups 318 GII, GIII and GIV had most types of MATE motifs, indicating that groups GII, GIII and GIV 319 might have diverse functions. MsMATEs in group GI only have five kinds of motifs, and most of 320 them are in the N-terminal, which is less than that of the other groups. It is interesting to note that 321 motif 9 was only found in group GI, except for MsMATE22. Ligaba et al and Sasaki et al 322 characterized the useful, structural and organic process nature of domains underlying Al sensitivity 
323 of Al-activated malate/anion transporters (TaALMT1), and indicated that the N-domain relies to

324 make conductive pathway and mediate particle transport even within the absence of the C-domain

325 (Ligaba et al. 2013; Sasaki et al. 2014). The GI group transporters were predicated to be Al

326 detoxification-related based on the phylogenetic tree analysis, implying that motif 9 might play a

327 crucial role in Al detoxification in alfalfa. Previous research has offered a good vary of references

328 that amino acid motifs and functionally important domains are concerned in diverse biological

329 processes, like transcriptional activity, protein-protein interactions, and nuclear localization (Liu

330 et al. 2010). These motifs or domains are typically preserved among members of a subgroup of

331 giant families, moreover proteins of those motif are additional possible to share similar functions.

332 To date, the exact roles of these conserved motifs in MsMATEs have not been reported. The next

333 step of functional identification of these motifs would benefit our considerate of the structure-

334 function relationship of MsMATEs.

335 The identification of the expression profiles of genes, especially those with tissue-specific,

336 will be useful for classification of genes that are concerned with the regulation of the precise nature

337 of individual tissue. Increasing lines of evidence suggested that overexpression of tissue-

338 specifically genes can promote tissue remodelling and functional improvement (Shitan et al. 2014;

339 Shoji et al. 2009). Given the different tissue-specific expression and varying subcellular

340 localizations (Table S3), the MATEs identified here might possess diverse functions during

341 various physiological and cellular processes in alfalfa. For example, AtDTX50, a MATE

342 homologous gene of Arabidopsis, was expressed primarily in vascular tissues and guard cells and

343 was powerfully up-regulated by exogenous ABA (abscisic acid) in leaves (Zhang et al. 2014). $M$.

344 truncatula MATE02, which is uttered mostly in leaves and flowers, shows advanced transport

345 ability for anthocyanin pigmentation and pale flower colour, however, lower potency for

346 alternatives glycosides (Zhao et al. 2011). Recently, it had been discovered in genome-wide

347 expression analysis that OsMATE1 and OSMATE2 genes altered growth and morphology in

348 transgenic Arabidopsis, suggesting their potential roles in regulating plant expansion in transgenic 
349 lines (Tiwari et al. 2014). In this study, the gene translation of the MsMATEs showed a high 350 inconsistency in transcription plenty (Fig. 4). Some genes exhibited constituted expression 351 profiles, such as MSMATE 05, 22, 31, 38 and 82, which were expressed in all examined tissues, 352 while some others were found to be expressed specifically high only in the root (MSMATE 01, 25, $35326,46,62$, and 63), flower (MsMATE 02, 34, and 64) and nodule (MsMATE 15, 42, 43, 55, 56, 59, 35476,77 and 78). The various expression profiles of the MSMATE genes implicated their functional 355 diversity, which could provide useful guidance for functional identification of candidate genes for 356 specific traits in genetic engineering of alfalfa.

357 Al quickly affects a variety of cellular processes and quickly inhibits cell elongation in the 358 root, which is taken into account to be the first target of Al stress (Chandran et al. 2008a; Chandran 359 et al. 2008b; Ryan et al. 1993). In our study, ten MsMATE genes that were predicated to be Al 360 detoxification-related based on the phylogenetic analysis were chosen for qRT-PCR confirmation.

361 The results proved that the expression of five genes (MSMATE03, MsMATE05, MsMATE07, 362 MSMATE09 and MSMATE22) in the root tip after Al stress was significantly induced (Fig. 5), 363 signifying that these genes might play a vital role in conferring Al tolerance in alfalfa and so would 364 be attention-grabbing candidate genes for more determination. The MsMATE03, MsMATE07, 365 MsMATE09 and MSMATE22 shared 64\%, 93\%, 97\%, 89\% identity with a putative M. truncatula 366 MtMATE66 (Medtr2g097900.1) respectively. The root growth of the mtmate66 mutant was less 367 than that of wild type under $\mathrm{Al}^{3+}$ treatment, and chlorotic was observed under Fe-deficient 368 condition in seedlings. Overexpression of MtMATE66 rendered hairy roots more tolerant to $\mathrm{Al}^{3+}$ 369 toxicity (Wang et al. 2017). MSMATE03 and MSMATE05 shared 65\% and 67\% identity with a 370 putative VUMATE1 (Vigna umbellate MATE1), respectively (Fan et al. 2014). The expression of 371 these two genes up to the highest-level by $8 \mathrm{~h}$ of exposure to $\mathrm{Al}^{3+}$ stress. Previously study showed 372 that the expression of VUMATE1 was increased along with the increaseed external Al 373 concentrations after $4 \mathrm{~h}$ of exposure, indicated that these two genes may function as early Al374 responsive transporters in root. The ortholog of MsMATE03 and MsMATE05 in Arabidopsis is 
375 FRD3, which shown to be a citrate efflux transporter. The plants overexpressed with ATFRD3 had

376 significantly higher amounts of citrate in their root exudates and possessed an enhanced resistance

377 to aluminium compared to untransformed controls (Durrett et al. 2007). Previously research shown

378 that the sequence similarity-based methodology had an associate accuracy rate of $83 \%$ for stress-

379 related GmNAC sequence identification of soybean (Le et al. 2011). So, these results in our study

380 would provide useful information by identifying candidate Al stress related MsMATE genes and

381 to engineer alfalfa plants for enhanced Al stress resistance.

382 Furthermore, MATE family members may possess diverse functions in plant cellular and

383 physiological processes because of their different subcellular localizations, substrates, and tissue-

384 specific of gene translation. Interestingly, some genes in the MATE family, such as EDS5 and 385 ADS1 in Arabidopsis, can proceed as a positive or negative regulator in response to disease 386 resistance (Ishihara et al. 2010; Sun et al. 2011). In our study, the expression patterns of five 387 MsMATE genes (MsMATE01, MsMATE02, MsMATE04, MsMATE06 and MsMATE08) were also 388 found to be repressed after Al treatment in alfalfa root tips (Fig. 5). However, the specific reasons 389 for this down-regulation of these genes are still unclear, and whether these MsMATE genes can 390 function as negative regulators in Al stress in alfalfa still needs to be further investigated.

\section{Conclusions}

392 To investigate this study, we tend to perform a comprehensive transcriptome-wide survey of 393 MsMATE transporters in an important legume species, alfalfa. A complete of 88 transporters were 394 categorized and classified into four main classes comprising eleven smaller subgroups consistent 395 with organic process interaction and structural characteristics. The expression profile of $M S M A T E$ 396 genes in various tissues/organs indicates that this gene family is wide concerned in alfalfa 397 upgrading. The expression of MsMATE03, MsMATE05, MsMATE07, MsMATE09, and 398 MSMATE22 was significantly induced after Al treatment, indicating that these genes would 399 possibly play a vital role in conferring Al tolerance in alfalfa. The elaborate results conferred here 
400

401

402

403

404

405

406

407

408

409

410

411

412

413

414

415

416

417

418

419

420

421

422

423

424

425

426

427

428

429

430

431

432

433

434

would offer valuable data for the useful investigation and application of this transporter family in alfalfa.

\section{References}

Bailey TL, Johnson J, Grant CE, Noble WS. 2015. The MEME Suite. Nucleic Acids Research 43:W39W49.

Benedito VA, Li H, Dai X, Wandrey M, He J, Kaundal R, Torres-Jerez I, Gomez SK, Harrison MJ, Tang Y. 2010. Genomic inventory and transcriptional analysis of Medicago truncatula transporters. Plant Physiology 152:1716-1730.

Burko Y, Geva Y, Refaelcohen A, Shleizerburko S, Shani E, Berger Y, Halon E, Chuck G, Moshelion M, Ori N. 2011. From organelle to organ: ZRIZI MATE-Type transporter is an organelle transporter that enhances organ initiation. Plant \& Cell Physiology 52:518-527.

Chandran D, Sharopova N, Ivashuta S, Gantt JS, Vandenbosch KA, Samac DA. 2008a. Transcriptome profiling identified novel genes associated with aluminum toxicity, resistance and tolerance in Medicago truncatula. Planta 228:151-166.

Chandran D, Sharopova N, VandenBosch KA, Garvin DF, and Samac DA. 2008b. Physiological and molecular characterization of aluminum resistance in Medicago truncatula. BMC plant biology 8:89.

Chen L, 0578.

Diener AC, Gaxiola RA, and Fink GR. 2001. Arabidopsis ALF5, a multidrug efflux transporter gene family member, confers resistance to toxins. Plant Cell 13:1625-1637.

Durrett TP, Gassmann W, Rogers EEJPP. 2007. The FRD3-mediated efflux of citrate into the root vasculature is necessary for efficient iron translocation. Plant Physiology 144:197-205.

Fan W, Lou HQ, Gong YL, Liu MY, Wang ZQ, Yang JL, Zheng SJ. 2014. Identification of early Al responsive genes in rice bean (Vigna umbellata) roots provides new clues to molecular mechanisms of Al toxicity and tolerance. Plant, Cell and Environment 37:1586-1597.

Furukawa J, Yamaji N, Wang H, Mitani N, Murata Y, Sato K, Katsuhara M, Takeda K, Ma JF. 2007. An aluminum-activated citrate transporter in barley. Plant \& Cell Physiology 48:1081-1091.

Goodstein DM, Shu S, Howson R, Neupane R, Hayes RD, Fazo J, Mitros T, Dirks W, Hellsten U, Putnam N. 2012. Phytozome: a comparative platform for green plant genomics. Nucleic Acids Research 40:D1178-D1186.

Hartel PG, Bouton JH. 1991. Rhizobium meliloti inoculation of alfalfa selected for tolerance to acid, aluminium-rich soils. Plant and Soil 116:283-285.

Hiasa M, Matsumoto T, Komatsu T, Moriyama Y. 2006. Wide variety of locations for rodent MATE1, a transporter protein that mediates the final excretion step for toxic organic cations. American Journal of Physiology 291:678-686. 
435

436

437

438

439

440

441

442

443

444

445

446

447

448

449

450

451

452

453

454

455

456

457

458

459

460

461

462

463

464

465

466

467

468

469

470

471

472

Horton P, Park KJ, Obayashi T, Fujita N, Harada H, Adamscollier CJ, Nakai K. 2007. WoLF PSORT: protein localization predictor. Nucleic Acids Research 35:585-587.

Huang CF, Yamaji N, Mitani N, Yano M, Nagamura Y, and Ma JF. 2009. A bacterial-type ABC transporter is involved in aluminum tolerance in rice. The Plant Cell 21:655-667.

Ishihara T, Sekine K, Hase S, Kanayama Y, Seo S, Ohashi Y, Kusano T, Shibata DJ, Takahashi H. 2010. Overexpression of the Arabidopsis thaliana EDS5 gene enhances resistance to viruses. Plant Biology 10:451-461.

Kochian LV. 1995. Cellular mechanisms of aluminum toxicity and resistance in plants. Annual Review of Plant Physiology \& Plant Molecular Biology 46:237-260.

Kochian LV, Hoekenga OA, Piñeros MA. 2004. How do crop plants tolerate acid soils? Mechanisms of aluminum tolerance and phosphorous efficiency. Annual Review of Plant Biology 55:459-493.

Kochian LV, Piñeros MA, Jiping L, Magalhaes JV. 2015. Plant adaptation to acid soils: the molecular basis for crop aluminum resistance. Annual Review of Plant Biology 66:571.

Kochian LV, Piñeros MA, Hoekenga OA, Lambers H, Colmer TD. 2005. The physiology, genetics and molecular biology of plant aluminum resistance and toxicity. Plant \& Soil 274:175-195.

Krogh A, Larsson B, Von HG, Sonnhammer EL. 2001. Predicting transmembrane protein topology with a hidden Markov model: application to complete genomes. Journal of Molecular Biology 305:567-580.

Kumar S, Stecher G, Tamura K. 2016. MEGA7: Molecular Evolutionary Genetics Analysis version 7.0 for bigger datasets. Molecular Biology \& Evolution 33:1870.

Le DT, Nishiyama R, Watanabe Y, Mochida K, Yamaguchi-Shinozaki K, Shinozaki K, Tran LS. 2011. Genome-wide survey and expression analysis of the plant-specific NAC transcription factor family in soybean during development and dehydration stress. DNA Research 18:263-276.

Li L, He Z, Pandey GK, Tsuchiya T, Luan S. 2002. Functional cloning and characterization of a plant efflux carrier for multidrug and heavy metal detoxification. Journal of Biological Chemistry 277:5360.

Ligaba A, Dreyer I, Margaryan A, Schneider DJ, Kochian L, Piñeros M. 2013. Functional, structural and phylogenetic analysis of domains underlying the $\mathrm{Al}$ sensitivity of the aluminum-activated malate/anion transporter, TaALMT1. Plant Journal 76:766-780.

Liu J, Luo X, Shaff J, Liang C, Jia X, Li Z, Magalhaes J, and Kochian LV. 2012. A promoter-swap strategy between the AtALMT and AtMATE genes increased Arabidopsis aluminum resistance and improved carbon-use efficiency for aluminum resistance. Plant Journal 71:327-337.

Liu J, Magalhaes JV, Shaff J, Kochian LV. 2009. Aluminum-activated citrate and malate transporters from the MATE and ALMT families function independently to confer Arabidopsis aluminum tolerance. The Plant Journal 57:389-399.

Liu J, Yang L, Wei W, Gai J, Yan L. 2016. Genome-wide analysis of MATE transporters and expression patterns of a subgroup of MATE genes in response to aluminum toxicity in soybean. Bmc Genomics 17:223.

Liu L, White MJ, and Macrae TH. 2010. Transcription factors and their genes in higher plants functional domains, evolution and regulation. European Journal of Biochemistry 262:247-257. 
473

474

475

476

477

478

479

480

481

482

483

484

485

486

487

488

489

490

491

492

493

494

495

496

497

498

499

500

501

502

503

504

505

506

507

508

509

510

Liu W, Xiong C, Yan L, Zhang Z, Ma L, Wang Y, Liu Y, Liu Z. 2017. Transcriptome analyses reveal candidate genes potentially involved in Al stress response in alfalfa. Frontiers in Plant Science 8:26.

Lu P, Magwanga RO, Guo X, Kirungu JN, Lu H, Cai X, Zhou Z, Wei Y, Wang X, Zhang Z. 2018. Genome-wide analysis of multidrug and toxic compound extrusion (MATE) family in Gossypium raimondii and Gossypium arboreumand its expression analysis under salt, cadmium, and drought stress. G3 (Bethesda, Md.) 8:2483-2500.

Ma JF. 2000. Role of organic acids in detoxification of aluminum in higher plants. Plant \& Cell Physiology 41:383-390.

Ma JF, Ryan PR, Delhaize E. 2001. Aluminium tolerance in plants and the complexing role of organic acids. Trends in Plant Science 6:273-278.

Magalhaes JV, Liu J, Guimarães CT, Lana UG, Alves VM, Wang YH, Schaffert RE, Hoekenga OA, Piñeros MA, Shaff JE. 2007. A gene in the multidrug and toxic compound extrusion (MATE) family confers aluminum tolerance in sorghum. Nature Genetics 39:1156-1161.

Marinova K, Pourcel L, Weder B, Schwarz M, Barron D, Routaboul JM, Debeaujon I, Klein M. 2007. The Arabidopsis MATE transporter TT12 acts as a vacuolar flavonoid/ $\mathrm{H}^{+}$-antiporter active in proanthocyanidin-accumulating cells of the seed coat. Plant Cell 19:2023-2038.

Maron LG, Piñeros MA, Guimarães CT, Magalhaes JV, Pleiman JK, Mao CZ, Shaff J, Belicuas SNJ, Kochian LV. 2010. Two functionally distinct members of the MATE (multi-drug and toxic compound extrusion) family of transporters potentially underlie two major aluminum tolerance QTLs in maize. Plant Journal 61:728-740.

Min X, Zhang Z, Liu Y, Wei X, Liu Z, Wang Y, Liu W. 2017. Genome-wide development of microRNAbased SSR markers in Medicago truncatula with their transferability analysis and utilization in related legume species. International Journal of Molecular Sciences 18:2440.

Mohanta TK, Arora PK, Mohanta N, Parida P, Bae HJBG. 2015. Identification of new members of the MAPK gene family in plants shows diverse conserved domains and novel activation loop variants. $B M C$ Genomics 16:58.

Morita M, Shitan N, Sawada K, Van Montagu MC, Inzé D, Rischer H, Goossens A, Oksmancaldentey KM, Moriyama Y, Yazaki K. 2009. Vacuolar transport of nicotine is mediated by a multidrug and toxic compound extrusion (MATE) transporter in nicotiana tabacum. Proceedings of the National Academy of Sciences of the United States of America 106:2447-2452.

Morita Y, Kodama K, Shiota S, Mine T, Kataoka A, Mizushima T, Tsuchiya T. 1998. NorM, a putative multidrug efflux protein, of Vibrio parahaemolyticus and its homolog in Escherichia coli. Antimicrobial Agents and Chemotherapy 42:1778.

Motawie MS, Olsen CE, Noureldin HH, Møller BL. 2016. The biosynthetic gene cluster for the cyanogenic glucoside dhurrin in contains its co-expressed vacuolar MATE transporter. Scientific Reports 6:37079.

Nawrath C, Heck S, Parinthawong N, Métraux JP. 2002. EDS5, an essential component of salicylic aciddependent signaling for disease resistance in Arabidopsis, is a member of the MATE transporter family. Plant Cell 14:275-286. 
511 O'Rourke JA, Fu F, Bucciarelli B, Yang SS, Samac DA, Lamb JAFS, Monteros MJ, Graham MA,

512 Gronwald JW, Krom N. 2015. The Medicago sativa gene index 1.2: a web-accessible gene expression

$513 \quad$ atlas for investigating expression differences between Medicago sativa subspecies. BMC Genomics 16:1-

51417.

515 Ryan PR, Ditomaso JM, Kochian LV. 1993. Aluminium toxicity in roots: an investigation of spatial

516 sensitivity and the role of the root cap. Journal of Experimental Botany 44:437-446.

517 Sade H, Meriga B, Surapu V, Gadi J, Sunita MS, Suravajhala P, Kavi Kishor PB. 2016. Toxicity and

518 tolerance of aluminum in plants: tailoring plants to suit to acid soils. BioMetals 29:187-210.

519 Sasaki T, Tsuchiya Y, Ariyoshi M, Ryan PR, Furuichi T, Yamamoto Y. 2014. A domain-based approach

520 for analyzing the function of aluminum-activated malate transporters from wheat (Triticum aestivum)

$521 \quad$ and Arabidopsis thaliana in xenopus oocytes. Plant \& Cell Physiology 55:2126-2138.

522 Sawaki Y, Kihara-Doi T, Kobayashi Y, Nishikubo N, Kawazu T, Kobayashi Y, Koyama H, Sato S. 2013.

523 Characterization of Al-responsive citrate excretion and citrate-transporting MATEs in Eucalyptus

524 camaldulensis. Planta 237:979-989.

525 Seo PJ, Park J, Park MJ, Kim YS, Kim SG, Jung JH, Park CM. 2012. A Golgi-localized MATE

526 transporter mediates iron homoeostasis under osmotic stress in Arabidopsis. Biochemical Journal

$527 \quad 442: 551-561$.

528

529

530

531

532

Shitan N, Minami S, Morita M, Hayashida M, Ito S, Takanashi K, Omote H, Moriyama Y, Sugiyama A, Goossens A, Moriyasu M, Yazaki K. 2014. Involvement of the leaf-specific multidrug and toxic compound extrusion (MATE) transporter Nt-JAT2 in vacuolar sequestration of nicotine in Nicotiana tabacum. Plos One 9:e108789.

533

Shoji T. 2014. ATP-binding cassette and multidrug and toxic compound extrusion transporters in plants.

534 International Review of Cell and Molecular Biology 303-346.

Shoji T, Inai K, Yazaki Y, Sato Y, Takase H, Shitan N, Yazaki K, Goto Y, Toyooka K, Matsuoka K,

535

536

537 Hashimoto T. 2009. Multidrug and toxic compound extrusion-type transporters implicated in vacuolar sequestration of nicotine in tobacco roots. Plant Physiology, 149:708-718.

538

539

540

541

542

543

Sievers F, Wilm A, Dineen D, Gibson TJ, Karplus K, Li W, Lopez R, Mcwilliam H, Remmert M, Söding J. 2011. Fast, scalable generation of high-quality protein multiple sequence alignments using Clustal Omega. Molecular Systems Biology 7:539.

Sun X, Gilroy EM, Chini A, Nurmberg PL, Hein I, Lacomme C, Birch PR, Hussain A, Yun BW, Loake GJ. 2011. ADS1 encodes a MATE-transporter that negatively regulates plant disease resistance. The New phytologist 192:471-482.

Thompson EP, Christopher W, Vadim D, Davies JM, Glover BJ. 2010. An Arabidopsis flavonoid

545 transporter is required for anther dehiscence and pollen development. Journal of Experimental Botany

546 61:439-451.

Tiwari M, Sharma D, Singh M, Tripathi RD, Trivedi PK. 2014. Expression of OsMATE1 and OsMATE2

548 alters development, stress responses and pathogen susceptibility in Arabidopsis. Scientific Reports 4:3964. 
549 Von Mering C, Jensen LJ, Snel B, Hooper SD, Krupp M, Foglierini M, Jouffre N, Huynen MA, Bork P.

550 2005. STRING: known and predicted protein-protein associations, integrated and transferred across

$551 \quad$ organisms. Nucleic Acids Research 33:433-437.

552 Vonuexkull HR, Mutert E. 1995. Global extent, development and economic impact of acid soils. Plant \&

553 Soil 171:1-15.

554 Wang D, Khurshid M, Sun ZM, Tang Y, Zhou ML, Wu YM. 2016. Genetic engineering of alfalfa

555 (Medicago sativa L.). Protein \& Peptide Letters 23:495-502.

556 Wang J, Hou Q, Li P, Yang L, Sun X, Benedito VA, Wen J, Chen B, Mysore KS, Zhao J. 2017. Diverse

557 functions of multidrug and toxin extrusion (MATE) transporters in citric acid efflux and metal

558 homeostasis in Medicago truncatula. Plant Journal 90:79.

559 Wang R, Liu X, Liang S, Ge Q, Li Y, Shao J, Qi Y, An L, Yu F. 2015. A subgroup of MATE transporter

560 genes regulates hypocotyl cell elongation in Arabidopsis. Journal of Experimental Botany 66:6327.

561 Wang Z, Qian C, Guo X, Liu E, Mao K, Mu C, Chen N, Zhang W, Liu H. 2016. ELS1, a novel MATE

562 transporter related to leaf senescence and iron homeostasis in Arabidopsis thaliana. Biochemical \&

563 Biophysical Research Communications 476:319-325.

564 Wood S, Sebastian K, Scherr SJ, Wood S, Sebastian K, Scherr SJ. 2000. Pilot analysis of global

565 ecosystems: agroecosystems. World Resources Institute 4:275.

566 Xia J, Yamaji N, Ma JF. 2011. Further characterization of an aluminum influx transporter in rice. Plant

567 Signaling \& Behavior 6:160-163.

568 Yokosho K, Yamaji N, Kashino-Fujii M, Ma JF. 2016. Functional analysis of a MATE gene $O s F R D L 2$

569 revealed its involvement in Al-induced secretion of citrate, but less contribution to Al tolerance in rice.

$570 \quad$ Plant \& Cell Physiology 57:976.

571 Yokosho K, Yamaji N, Ma JF. 2011. An Al-inducible MATE gene is involved in external detoxification of

$572 \quad \mathrm{Al}$ in rice. Plant Journal 68:1061-1069.

573 Zhang H, Zhu H, Pan Y, Yu Y, Luan S, Li L. 2014. DTX/MATE-type transporter facilitates abscisic acid

574 efflux and modulates ABA sensitivity and drought tolerance in Arabidopsis. Molecular Plant 7:1522-

$575 \quad 1532$.

576

577

578

Zhao J, Huhman D, Shadle G, He XZ, Sumner LW, Tang Y, Dixon RA. 2011. MATE2 mediates vacuolar

579 sequestration of flavonoid glycosides and glycoside malonates in Medicago truncatula. Plant Cell

580

581

582

583 23:1536-1555.

Zheng SJ, Yang JL, He YF, Yu XH, Zhang L, You JF, Shen RF, Matsumoto H. 2005. Immobilization of aluminum with phosphorus in roots is associated with high aluminum resistance in buckwheat. Plant Physiology 138:297-303.

Zhu H, Jiandong WU, Jiang Y, Jin J, Zhou W, Wang YU, Han G, Zhao Y, Cheng B. 2016. Genomewide analysis of MATE -type gene family in maize reveals microsynteny and their expression patterns under

584 aluminum treatment. Journal of Genetics 95:691-704.

585

586

Figure Legends 
587 Fig. 1. Phylogenetic tree of MATE proteins from Arabidopsis, rice and alfalfa. The

588 phylogenetic tree was constructed using MEGA6.0 and the neighbour-joining method with 1000 589 bootstrap replicates. The tree was divided into 4 subfamilies comprising 11 smaller subgroups. 590 Members of Arabidopsis, alfalfa and rice are denoted by red, blue and yellow triangles, 591 respectively.

592 Fig. 2. Functional annotation of MATE proteins from alfalfa and other plants. The 593 phylogenetic tree was constructed using MEGA6.0 and the neighbour-joining method with 1000 594 bootstrap replicates. The tree was divided into 4 subfamilies comprising 12 smaller subgroups.

595 Fig. 3. Phylogenetic relationships and domain compositions of the MsMATE proteins. (A) 596 The unrooted phylogenetic tree was constructed with 1000 bootstrap replicates based on a multiple 597 alignment of 88 MATE genes amino acid sequences. The four major subgroups are marked with 598 different-coloured backgrounds. (B) The conserved motifs in the MsMATE proteins were 599 identified using MEME. Grey lines represent the non-conserved sequences. Each motif is indicated 600 by a coloured box numbered at the bottom. The length of the motifs in each protein is exhibited 601 proportionally.

602 Fig. 4. Heatmap representation and hierarchical clustering of the $M S M A T E$ genes in various 603 tissues of alfalfa. The transcript data of 6 tissues were used to re-construct the expression patterns 604 of MSMATE genes. The black boxes indicate that the transcript abundance is zero. The bar at the 605 bottom of the heat map represents the relative expression values; values $<1.27$ represent down606 regulated expression and values $>1.27$ represent up-regulated expression.

607 Fig. 5. The relative expression ratio of ten representative $M$ sMATE genes in Al stress (CK, 608 before treatment; Al, under stress treatments for 4, 8 and 24 hours) have been calculated 609 with reference (actin gene). Different capital letters indicate significant differences between 
610 different treatment times $(* P<0.05)$. The name of the gene is written on the top of each bar diagram

611 (error bars indicate the standard deviation from three replicates).

612 Fig. S1. Overview of twelve conserved motifs identified through MEME.

613 Fig. S2. Functional interaction networks of 10 Al detoxification related MsMATE proteins

614 correlated with flavonoid biosynthesis. The highly matched five ortholog MATE proteins are

615 showed in red ellipse. 


\section{Figure 1}

Phylogenetic tree of MATE proteins from Arabidopsis, rice and alfalfa.

The phylogenetic tree was constructed using MEGA6.0 and the neighbour-joining method with 1000 bootstrap replicates. The tree was divided into 4 subfamilies comprising 11 smaller subgroups. Members of Arabidopsis, alfalfa and rice are denoted by red, blue and yellow triangles, respectively. 


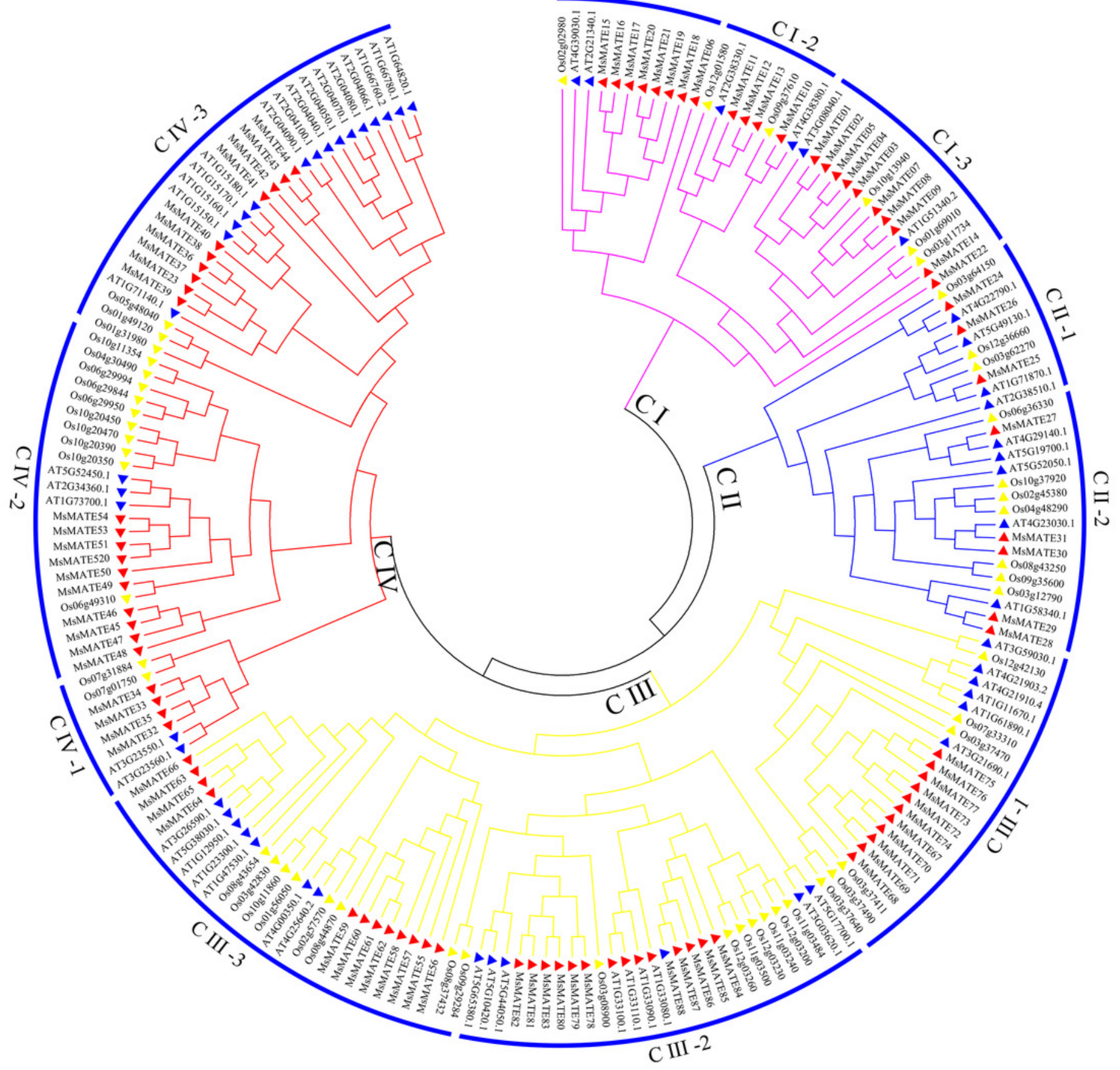




\section{Figure 2}

Functional annotation of MATE proteins from alfalfa and other plants.

The phylogenetic tree was constructed using MEGA6.0 and the neighbour-joining method with 1000 bootstrap replicates. The tree was divided into 4 subfamilies comprising 12 smaller subgroups. 
Citrate transporter

Xenobiotics and alkaloid transporter
Diverse physiological functions

Transport and accumulation of flavonoid and anthocyanin

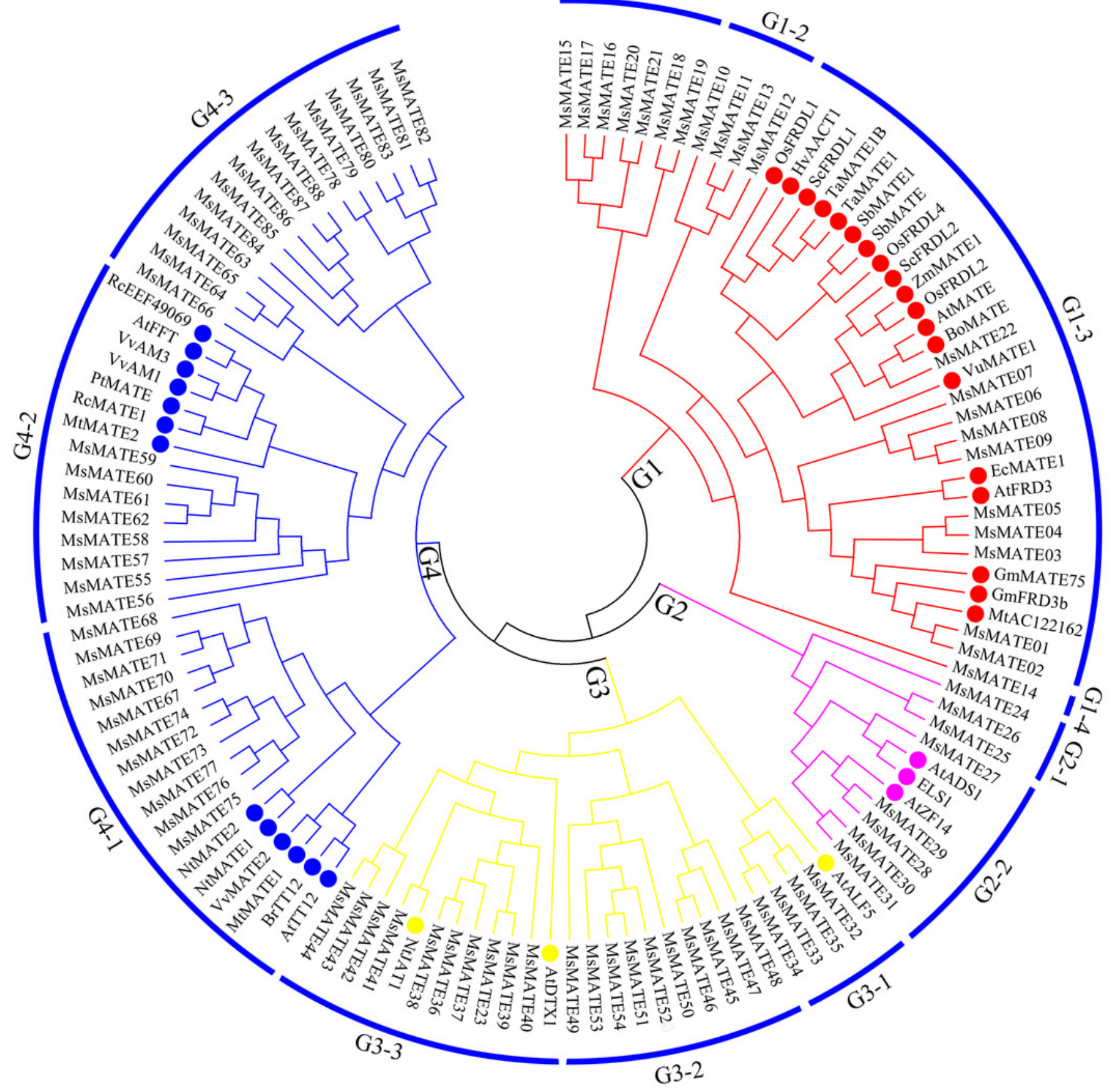




\section{Figure 3}

Phylogenetic relationships and domain compositions of the MsMATE proteins.

(A) The unrooted phylogenetic tree was constructed with 1000 bootstrap replicates based on a multiple alignment of 88 MATE genes amino acid sequences. The four major subgroups are marked with different-coloured backgrounds. (B) The conserved motifs in the MSMATE proteins were identified using MEME. Grey lines represent the non-conserved sequences. Each motif is indicated by a coloured box numbered at the bottom. The length of the motifs in each protein is exhibited proportionally. 


\section{A}

B

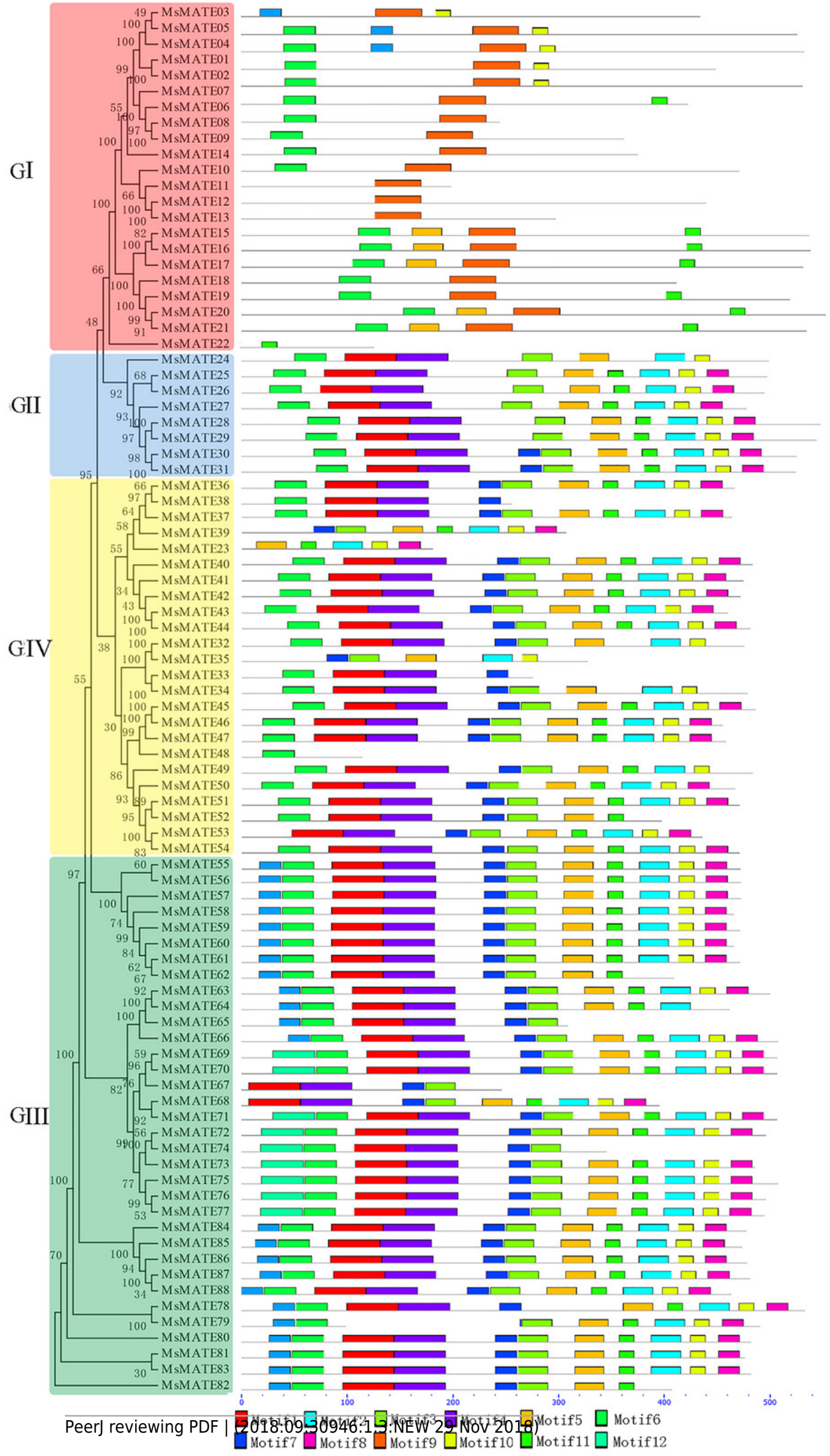




\section{Figure 4}

Heatmap representation and hierarchical clustering of the MSMATE genes in various tissues of alfalfa.

The transcript data of 6 tissues were used to re-construct the expression patterns of MSMATE genes. The black boxes indicate that the transcript abundance is zero. The bar at the bottom of the heat map represents the relative expression values; values $<1.27$ represent downregulated expression and values $>1.27$ represent up-regulated expression. 


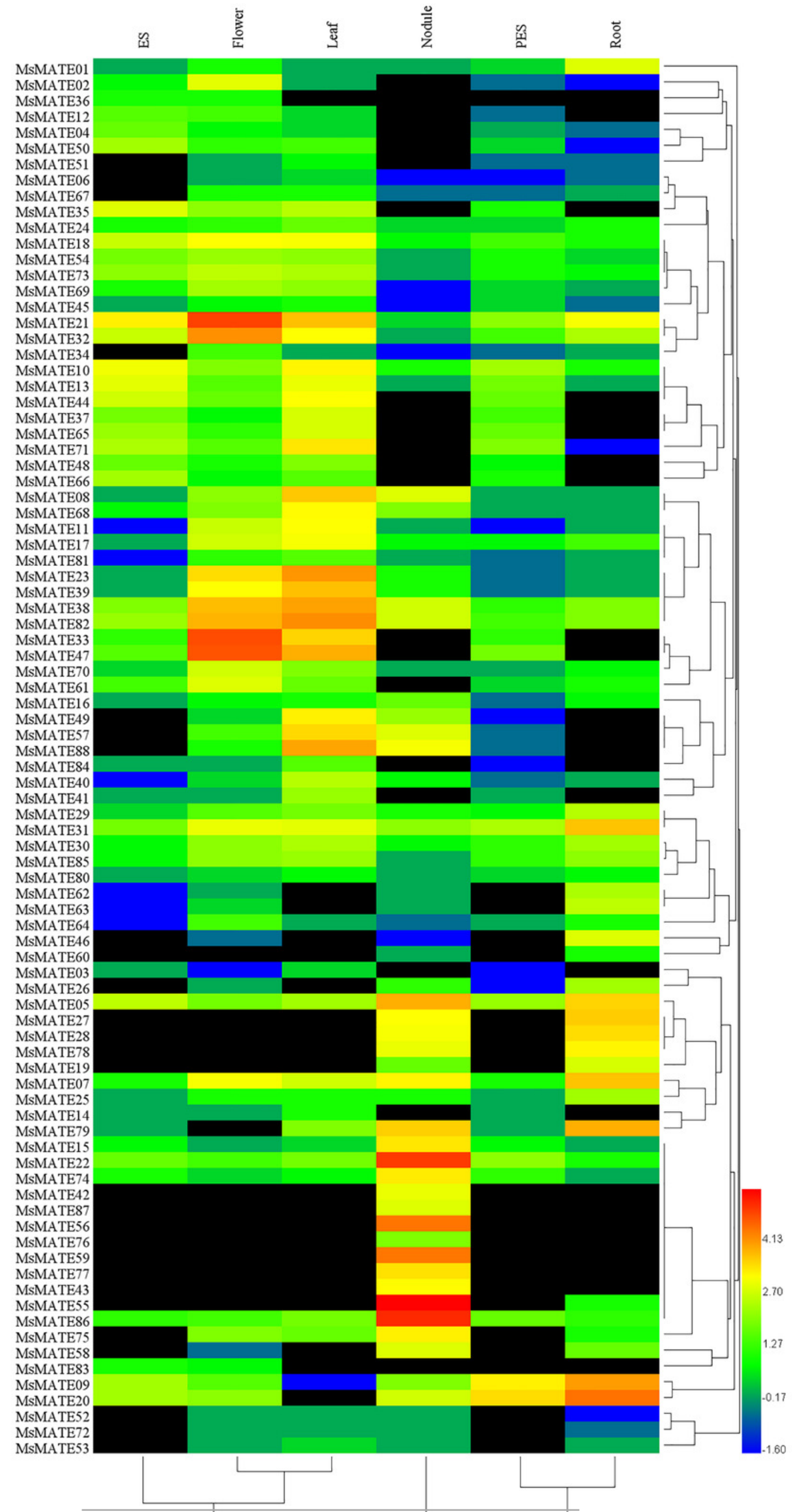




\section{Figure 5}

The relative expression ratio of ten representative MSMATE genes in Al stress (CK, before treatment; $\mathrm{Al}$, under stress treatments for 4,8 and 24 hours) have been calculated with reference (actin gene).

Different capital letters indicate significant differences between different treatment times (* $\mathrm{P}<0.05$ ). The name of the gene is written on the top of each bar diagram (error bars indicate the standard deviation from three replicates).
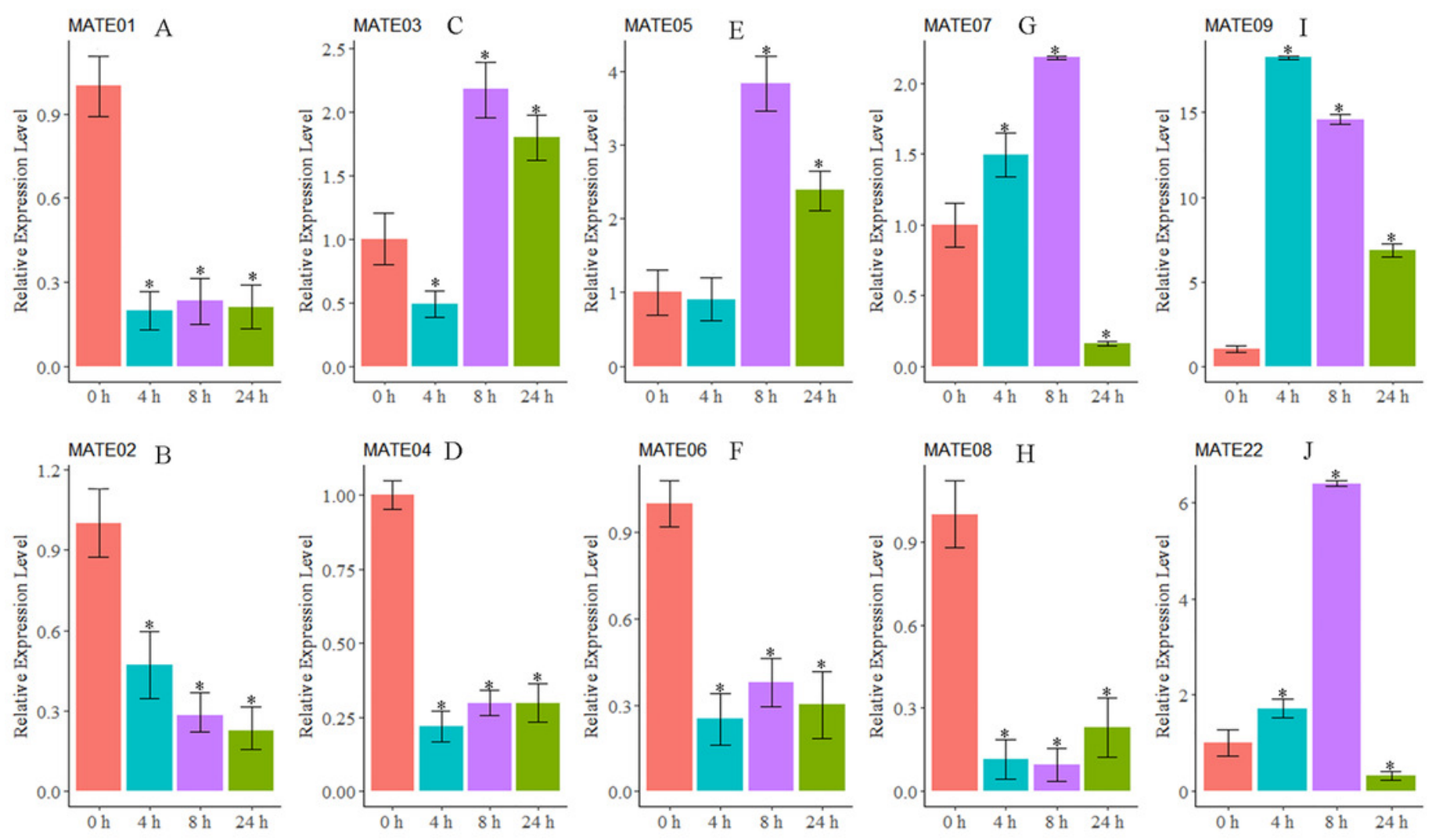